\title{
NOTES OF REMARKS ON PHYSICAL INSPECTION OF CHILDREN.
}

\author{
By Miss K. PHILLIPS, \\ Superintendent of Method-Education, L.C.C.
}

NECESSITY for re-organisation of schools for young children, in accordince with more adequate knowledge of laws of health and physical development which obtain to-day.

1. Owing to rarious causes, social and economic, thousands of children, three years of age, are found in English elementary schools.

2. Education, when it concerns such young children, and also those up to seven years of age, should be mainly a physical question.

Reasons:-(1) Because infectious illnesses become peculiarly prevalent owing to assembling so many young children together, under present conditions.

(2) Because it is in these years (three to seven years of age) that growth is most rapid, and wrong conditions as to cleanliness, food, clothing, hours of work, bad positions in sitting and standing, for instance, are allimportant in view of healthy derclopment.

(3) Becanse during these years eyes are frequently strained, and permanently injured, by insistence on wrong kind of occupation and work.

(4) Because the whole nervous system is strained by undue stimulation when nature is asking for rest, for sleep.

(5) Because if the conditions luring the most important hours of the day prevent self-adjustment, freedom, and variety of free movements of limbs, hands, fingers, eyes, that accumulation of experience camnot be made through muscular sense, and throngh sense organs, which must be, in order that knowledge may be.

Nature has provided for this, partly, in the "play-instinct" of all highly organised young animals.

Each of these points could be dwelt upon at length, to show that reorganisation of schools for tiny children is necessary. 
In them, too frequently the actual conditions of the social enrironment of the children ont of school are ignored. Also the conditions of healthy developing babyhood. They are organised f from the point of view of the senior school, and however excellent that may be it needs considerable modification when applied to bahies of three, four, and five years of age.

Owing to this, certain troubles arise on the school side of the question, which are umnecessary. Children fail to pass the examination at the given age when they should enter the senior school. They thus lose precious time which can be ill-spared in the short school life. To the health of mind and hody the loss is infinitely more serious. Liability to acquire and propagate infectious disease is increased. The teachers are too much occupied with preparation of the children, from their third year, for this coming examination in their screnth, to have leisure to note signs of disense, or physsical failure. Many children are stunted in mind and body. There is heariness and awliwardness, and dulness of perception, loss of power, of self-dependence, of initiative. These are some of the results of bringing crowils of tiny children together, under conditions which must induce attention solely to the acquisition of socalled knowledge, which obliges absence of movements, cxcept taken as drill, with silence, and absolute dependence on the word of command of the teacher in charge.

Remedies suggested:-I. Each institution should be governed by a head teacher, with numerous staff, who have had practical experience and training in real, not text-book, knowledge of the physical conditions of healthy derelopment.

II. The second in command should be at trained nurse, a permanent member of the staff.

III. Attached to each school there should be an attendant to assist in various ways under the direction of the nurse and head teacher.

IV. All children should be examined daily as to cleanliness of person and clothing, and physical state, depending on proper amount of sleep and nutrition; signs of illness should be noted.

When occasion suggests, clothing should be removed, and the condition of the whole body noted as to cleanliness, nutrition, physical malformation, etc.

V. Parents should be communicated with. Ignorant ones taught. private meetings of homely nature, real mothers' meetings, could be conducted under tactful and scientific direction. These could be a part of the work of all infants' schools. Parents would be instructed as to the preparation and qualities of suitable food, clothing, etc. 
VI. These private physical inspections of the children would be used for the detection of malformations, indications of disease, etc.

There should be periodic visits by an medical ufficer, when all such cases should be reported.

VII. The attendant should be particularly engaged in assisting to train the little ones in all decent personal habits. Infinite mischief results from ignoring the need of this training, which is given in all wellregulated nurseries, and by all excellent, right-thinking women of the working class. But in only too many cuses the social conditions, from over-crowding, etc., are such that the little ones are only trained to evil and indecency.

VIII. Also infinite mischief results on the physical, moral, and mental side from unsuitable clothing. Little boys' clothes are too tight and indescribably dirty.

IX. The desks, suats, tables, floors, and appiratus should be more frequently cleansed and disinfected. At present they are washed two ar three times during the year. The little boys' clothing is often secondhand to begin with; when remover at night it is used to help as bed covering; unlike the girls' clothes it is rarely if ever washed. The boys play in the street, they roll about in the gutters, on the pavements and road, the clothing is thus further contaminated by all that can be there picked up. In many cases pocket-handkerchiefs are unknown. These children in this contaminated clothing sit on the seats, rest arms on desks and books. Surely all that cin bo* wished, scrubbed, and disinfected should be so treated weekly.

Results:-If the bodies were thus cared for, and parents where necessary instructed, if necessary obliged to pay proper attention to cleanliness, decency, signs of malformation, signs of milnutrition, and want of sleep, the whole life would be healthier. Schools would provide for physical inspection and care as one of its most precious opportmities. They would provide for rest (hammocks for sleep), floor space, and time for free movements. It would provide occupation with large, coarser work for the exercise of larger muscles, all work which gives opportunity for selfadjustment during these first years of life.

The foundations for intellectual progress would thus be placed on a sound scientific basis, instead of the semi-medieval tradition which obtains too frequently at present.

Health would be greatly promoted generally, and infectious diseases be minimised under such conditions of rigilance and cleanliness.

The children would have time to live through the first stages of life 
more completely, the next, the real school stage would he adequately prepared for, and would thus in its turn be lived through with greater completeness of purpose and success.

If children were treated on some such lines as those indicated, all those of normal derelopment would ensily pass into the senior school at the required age, about $7 \frac{1}{2}$ rear's of age, with a reasonable prospect of a profitable and successful school career.

And this would be without comnting the infinite gain in the interests of health, morality, self-control.

The only possible way to milie our schools that which they should be in the life of the nation, is by the road of physical inspection, on some such lines as suggested.

Our education can only prosper, can only be effective, when it is based from the first, from babrhood, on sound medical knowledge, on scientific knowledge of the laws of development of mind and body. 